\title{
GAMBARAN PSYCHOLOGICAL WELL BEING PADA IBU RUMAH TANGGA DI KOTA BANDUNG
}

\section{PSYCHOLOGICAL WELL BEING DESCRIPTION OF HOUSEWIVES IN BANDUNG CITY}

\author{
Fauziah Taslim¹, Retno Hanggarani Ninin'2 \& Sri Rahayu Astuti ${ }^{3}$ \\ Fakultas Psikologi Universitas Padjadjaran \\ fauziah.taslim@gmail.com
}

\begin{abstract}
This study aims to measure the psychological well-being of the housewives. The research method used is a mixed method that combines quantitative and qualitative methods. The chosen mix method approach was sequential designs with an explanatory strategy, which was characterized by collecting and analyzing quantitative data followed by data collection and qualitative data analysis. This study uses convenience sampling technique. The sample consisted of 66 women aged 18-40 years. The technique used is descriptive, so that no hypothesis is tested. The measuring instrument used was the Psychological Well-Being Scale questionnaire. Based on the analysis of the results of the research conducted, it was found that the the majority had moderate psychological well-being. Based on the tests, there were no significant differences in psychological well-being based on demographic factors such as age at marriage, work status before marriage, and monthly income.
\end{abstract}

Keywords: housewife, psychological well-being

\begin{abstract}
ABSTRAK
Penelitian ini bertujuan untuk mengukur psychological well being istri yang berperan sebagai Ibu Rumah Tangga. Metode penelitian yang digunakan adalah mixed method yang menggabungkan metode kuantitatif dan kualitatif. Pendekatan mix method yang dipilih adalah sequential designs dengan strategi explanatory yang ditandai dengan pengumpulan dan analisa data kuantitatif terlebih dahulu kemudian dilanjutkan dengan pengumpulan data dan analisa data kualitatif. Penelitian ini menggunakan teknik convenience sampling. Sampel terdiri dari 66 orang perempuan berusia 18-40 tahun. Teknik yang digunakan adalah deskriptif, sehingga tak ada hipotesis yang diuji. Alat ukur yang digunakan adalah kuesioner Psychological Well-Being Scale (PWBS). Berdasarkan analisis hasil penelitian yang dilakukan, ditemukan bahwa ibu rumah tangga mayoritas memiliki psychological well-being yang sedang. Berdasarkan pengujiian, tidak ditemukan perbedaan psychological well-being yang signifikan berdasarkan faktor demografi seperti usia pernikahan, status kerja sebelum menikah, dan penghasilan bulanan.
\end{abstract}

Kata Kunci: Istri, psychological well-being 


\section{PENDAHULUAN}

Di Indonesia, banyak keluarga dengan istri yang mempunyai satu peran saja di dalam rumah tangga, yaitu peran sebagai Ibu Rumah Tangga (IRT). Peran tunggal tersebut bisa saja muncul karena seorang perempuan memang memilih hal itu, seusuai nilai tradisional yang banyak dianut oleh rumah tangga di Indonesia.

Sebagai Ibu rumah tangga, perempuan memiliki 3 peran turunan yang dijalani, yaitu peran produktif, peran reproduktif, serta peran sosial. Peran produktif merupakan peran yang menghasilkan barang yang digunakan untuk memenuhi kebutuhan manusia dan pendapatan yang digunakan untuk membiayai kehidupan keluarga. Selanjutnya, peran reproduktif merupakan peran mengelola rumah tangga atau keluarga beserta seluruh anggotanya. Peran reproduktif seorang wanita meliputi melahirkan dan mengurus anak-anak, memasak atau menyediakan makanan untuk keluaga, berbelanja kebutuhan rumah tangga, mencuci pakaian, dan menjaga kebersihan rumah, Sedangkan peran sosial di dalam komunitas merupakan berbagai peran yang harus dijalankan oleh seorang wanita sebagai anggota masyarakat, baik dalam bidang sosial, ekonomi, maupun politik. Peran tersebut berwujud dalam upaya untuk menyelenggarakan hubungan sosial yang baik dengan keluarga-keluarga lain serta berbagai kegiatan di dalam organisasi (Olson, Defrain, \& Skogrand, 2014).

Namun pada kenyataannya, pengambilan peran sebagai IRT tidak hanya terjadi karena seorang perempuan memilihnya, melainkan bisa terjadi karena seorang perempuan tidak memiliki alternatif lain yang lebih baik untuk dipilih atau paksaan. Detil situasinya bisa berupa tidak adanya pengasuh anak yang dapat dipercaya oleh perempuan menikah yang memiliki anak, tidak adanya biaya pengasuh, atau berupa tekanan sosial pada perempuan untuk tidak bekerja di luar rumah (Olson et al., 2014).

Berdasarkan penelusuran peneliti pada sejumlah sumber, situasi tersebut merupakan pengalaman yang juga dialami oleh banyak ibu rumah tangga lainnya. Wade (2016) mengatakan bahwa wanita cenderung kurang bahagia di dalam pernikahan dibandingkan dengan pria. Ketidakbahagiaan para wanita yang sudah menikah ini disebabkan wanita seringkali mengerjakan terlalu banyak pekerjaan rumah yang tidak dihargai dan mengorbankan waktu luang dan mimpinya untuk berkarir untuk sebuah pernikahan (Wade \& Sharp, 2013). Hal serupa juga diungkapkan oleh Putri (2013) bahwa rumah tangga di ASEAN dengan tipe pengaturan rumah tangga istri berperan 100\% 
mengurus pekerjaan rumah tangga sedangkan suami bertanggung jawab $100 \%$ untuk bekerja dan mencari nafkah, memunculkan perasaan tidak puas pada sang istri karena adanya beberapa keinginan istri tidak dapat diwujudkan setelah menikah, yaitu keinginan untuk melanjutkan pekerjaan/berkarir dan keinginan istri agar suami membantu melakukan tugas-tugas dalam rumah tangga (Putri \& Sudhana, 2013).

Berdasarkan penelitian lainnya, istri yang mempunyai satu peran saja di dalam rumah tangga juga mengalami penerimaan diri yang rendah akibat tidak puas akan dirinya yang merasa tidak bisa melakukan pencapaian apa-apa (Brown \& Ryan, 2003). Menurut Rogers dalam (Springer, 2013) penerimaan diri atau self acceptance merupakan komposisi utama dari kepuasan dan kebebasan individu dari emosi negatif.

Kemudian mereka juga merasa dikekang karena subyek seringkali tidak dapat mengambil keputusan sendiri untuk melakukan beberapa hal yang diinginkannya (April, Dharani, \& Peters, 2012), karena keputusan tersebut berasal dari orang lain di luar dirinya, yaitu suami atau keluarga besar. Ketika seseorang meyakini bahwa kehidupan mereka lebih dikendalikan oleh faktor-faktor di luar diri mereka, individu ini disebut mempunyai locus of control eksternal (Rotter, 1972). Locus of control sendiri menurut Rotter merupakan keyakinan individu mengenai sumber penyebab dari peristiwaperistiwa yang dialami dalam hidupnya. Seseorang dapat memiliki keyakinan bahwa dirinya merupakan faktor penentu utama dalam mengendalikan hidupnya (locus of control internal) ataupun meyakini bahwa faktor-faktor di luar dirinyalah yang mempunyai kendali akan peristiwa-peristiwa yang terjadi dalam hidup mereka (locus of control eksternal) (Rotter, 1972).

Kondisi mereka yang mengatakan dirinya tidak dapat memilih untuk melakukan hal yang diinginkannya sehingga membuatnya kurang puas ini juga didukung oleh Rogers. Rogers mengatakan bahwa salah satu karakteristik individu yang berfungsi sepenuhnya adalah ketika mempunyai freedom of choice, yaitu ketika seseorang percaya bahwa ia memiliki peranan dalam menentukan perilakunya serta bertanggungjawab atas pilihan yang diambilnya. Semakin seseorang sehat secara psikologis, semakin ia mempunyai kebebasan untuk memilih dan bertindak (Rogers, 2012).

Mereka juga merasa tidak puas dengan dirinya karena telah merasa 'kehilangan' dirinya, dan membuatnya menjadi individu yang tidak diinginkannya karena tidak berkembang. Selain freedom of choice seperti yang dibahas sebelumnya (Markus \& 
Schwartz, 2010), Rogers juga menyebutkan karakteristik lain individu yang berfungsi sepenuhnya adalah openness to experience. Menurut Rogers, seorang individu dapat berfungsi sepenuhnya yaitu ketika ia selalu berkembang (Rogers, 2009). Hal serupa juga diungkapkan oleh Jahoda dalam (Tengland \& Tengland, 2001) . Jahoda mengungkapkan bahwa salah satu dari enam kriteria positive mental health adalah adanya pertumbuhan dan perkembangan individu. Dalam hal ini, Jahoda menyebutkan bahwa setiap individu harus mempunyai dan memenuhi potensi dipunya untuk menjadi individu yang sehat secara mental (Tengland, 2011).

Dalam penelitian lain, mereka merasa dirinya kurang dapat mengontrol situasi di sekitarnya untuk menjadi lingkungan yang dapat mendukung usahanya untuk menjadi individu yang produktif. dalam Ryff (Ryff \& Singer, 2008) mengungkapkan bahwa kemampuan individu untuk memilih dan menciptakan lingkungan agar sesuai dengan kondisi dan kebutuhkannya merupakan salah satu kunci untuk mendapatkan mental yang sehat (Ryff \& Keyes, 1995). Ryff juga menambahkan faktor penguasaan lingkungan seperti yang diungkapkan oleh Jahoda merupakan salah satu komponen penting yang membuat seseorang dapat merasa sejahtera secara psikologis. Menurut Ryff, seorang individu dikatakan mampu menguasai lingkungannya jika individu tersebut memiliki kompetensi dan mampu mengatur lngkungannya, dapat mengendalikan situasi eksternal yang kompleks, dan dapat menggunakan kesempatan di lingkungannya secara efektif.

Singkat kata, dapat disimpulkan bahwa bahwa seorang ibu rumah tangga kemungkinan mengalami permasalahan yang dalam konseptualisasi well being berada pada domain self acceptance, locus of control, freedom of choice, positive mental health, serta environmental mastery. Ryff (1995) menjadikan domain tersebut sebagai dasar dibentuknya sebuah konstruk psikologi yang dinamakan Psychological Well Being (Ryff \& Singer, 1998). Psychological Well Being menurut Ryff adalah sebuah kondisi dimana individu mempunyai sikap yang positif terhadap diri sendiri sikap positif terhadap orang lain, dapat membuat keputusan sendiri dan mengatur tingkah lakunya sendiri, dapat menciptakan dan mengatur lingkungan yang kompatibel dengan kebutuhannya, memiliki tujuan hidup dan membuat hidup lebih bermakna, serta berusaha mengekplorasi dirinya (Ryff, 2013). Dengan demikian dapat dikatakan bahwa permasalahan yang dirasakan oleh seorang ibu rumah tangga kemungkinan mengalami permasalahan dalam psychological well being. 
Maka dari itu, penelitian ini bertujuan untuk mengidentifikasi gambaran (profil) kesejahteraan psikis para ibu rumah tangga di Kota Bandung.

\section{METODE PENELITIAN}

\section{Desain Penelitian}

Pendekatan yang dilakukan dalam penelitian ini adalah pendekatan mix method. Dalam penelitian ini, pendekatan mix method yang dipilih adalah sequential designs dengan strategi explanatory. Sequential design biasanya ditandai dengan pengumpulan dan analisa data kuantitatif terlebih dahulu kemudian dilanjutkan dengan pengumpulan data dan analisa data kualitatif yang akan digunakan untuk membangun dan menjelaskan hasil dari data kuantitatif sebelumnya.

Populasi dalam penelitian ini adalah ibu rumah tangga yang berada pada tahap perkembangan dewasa awal atau 18-40 tahun. Metode yang digunakan dalam penelitian ini adalah non-probability sampling yang didalamnya dilakukan dengan teknik convenience sampling. Sampel terdiri dari 66 orang perempuan

Wawancara bersifat semi terstruktur dengan item yang mengacu pada dimensidimensi psychological well-being. Subjek wawancara terdiri dari 2 orang untuk setiap skor sangat rendah dan rendah, skor rata-rata, dan skor tinggi dan sangat tinggi untuk masing-masing dimensi.

\section{Alat Ukur}

Alat ukur yang digunakan dalam penelitian untuk mendapatkan data kuantitatif adalah Psychological Well-Being Scale (PWBS) oleh Ryff (1989). Skala ini merupakan alat ukur yang terdiri dari enam dimensi yaitu self-acceptance, positive relation with others, personal growth, autonomy, environmental mystery, dan purpose in life. Dalam salah satu versi PWBS, Dimensi dimensi ini kemudian dikembangkan oleh Ryff menjadi 84 pernyataan. Berdasarkan bentuk skala, PWBS merupakan suatu skala Likert dengan enam pilihan jawaban. Enam pilihan jawaban tersebut terdiri dari STS (Sangat Tidak Setuju), TS (Tidak Setuju), ATS (Agak Tidak Setuju), AS (Agak Setuju), S (Setuju), dan SS (Sangat Setuju).

\section{Prosedur}

Pengambilan data dilakukan pada bulan November 2019 sampai Desember 2019 di bawah pengawasan Psikolog Klinis. Peneliti menyebarkan kuisioner secara acak 
melalui media sosial, yaitu Instagram dan Line. Kuisioner dibagikan dalam bentuk google form yang terdiri dari tiga bagian, yaitu inform consent, data demografi, dan Psychological Well-Being Scale (PWBS) oleh Ryff (1989). Partisipan diminta untuk mengisi kuisioner oleh dirinya sendiri (self-report). Kemudian subjek wawancara akan dipilih secara acak dari para responden yang tellah mengisi kuesioner. Subjek yang diwawancara berjumlah 8 orang.

\section{HASIL PENELITIAN}

Hasil

Tabel 1 Jumlah Responden Berdasarkan Demografi

\begin{tabular}{|c|c|c|c|}
\hline Variabel & Kategori & Frekuensi & $\begin{array}{l}\text { Persentase } \\
(\%)\end{array}$ \\
\hline \multirow{4}{*}{ Usia Pernikahan } & $1-3$ tahun & 38 & 58 \\
\hline & $4-7$ tahun & 21 & 32 \\
\hline & $8-10$ tahun & 5 & 9 \\
\hline & $\geq 10$ tahun & 2 & 1 \\
\hline \multirow{2}{*}{$\begin{array}{l}\text { Bekerja Sebelum } \\
\text { Menikah } \\
\end{array}$} & $\mathrm{Ya}$ & 57 & 85 \\
\hline & Tidak & 9 & 15 \\
\hline \multirow{4}{*}{ Penghasilan Keluarga } & $1-3$ Juta & 8 & 12,1 \\
\hline & $3-5$ Juta & 22 & 33,3 \\
\hline & $5-10$ Juta & 24 & 36,4 \\
\hline & Di atas 10 Juta & 12 & 18,2 \\
\hline \multirow{5}{*}{ Pendidikan } & SMA/SMK & 9 & 14 \\
\hline & Diploma & 6 & 9 \\
\hline & S1 & 43 & 65 \\
\hline & $\mathrm{S} 2$ & 7 & 11 \\
\hline & S3 & 1 & 2 \\
\hline \multirow{2}{*}{ Memiliki Anak } & $\mathrm{Ya}$ & 8 & 12 \\
\hline & Tidak & 58 & 88 \\
\hline \multirow{2}{*}{ Peran Sosial } & Ya & 57 & 87 \\
\hline & Tidak & 9 & 13 \\
\hline
\end{tabular}


Tabel 2 Uji Beda Berdasarkan Data Demografi

\begin{tabular}{llllllll}
\hline $\begin{array}{l}\text { Data } \\
\text { Demografi }\end{array}$ & Acceptance & $\begin{array}{l}\text { Positive } \\
\text { Relation }\end{array}$ & $\begin{array}{l}\text { Personal } \\
\text { Growth }\end{array}$ & Autonomy & $\begin{array}{l}\text { Env. } \\
\text { Mastery }\end{array}$ & Purpose & PWB \\
\hline $\begin{array}{l}\text { Usia } \\
\text { Pernikahan }\end{array}$ & .316 & .327 & .549 & .428 & .451 & .297 & .475 \\
\hline $\begin{array}{l}\text { Bekerja } \\
\text { Sebelum }\end{array}$ & .837 & .715 & .779 & .779 & .394 & .722 & .513 \\
$\begin{array}{l}\text { Menikah } \\
\text { Penghasilan }\end{array}$ & .654 & .968 & .870 & .336 & .361 & .807 & .569 \\
Keluarga & & .040 & .137 & .115 & .137 & .149 & .347 \\
\hline Pendidikan & .176 & .0403 & .311 & .875 & .219 & .392 \\
\hline $\begin{array}{l}\text { Kepemilikan } \\
\text { Anak }\end{array}$ & .267 & .403 & .516 & & & & \\
\hline Peran Sosial & .591 & .594 & .925 & .303 & .896 & .274 & .660 \\
\hline
\end{tabular}

Tabel 3 Gambaran Psychological Well Being

\begin{tabular}{llllllc}
\hline \multirow{2}{*}{ Variabel/Dimensi } & \multicolumn{7}{c}{ Kategori } \\
\cline { 2 - 7 } & Rendah & $\mathbf{( \% )}$ & Sedang & $\mathbf{( \% )}$ & Tinggi & (\%) \\
\hline Acceptance & 23 & 35 & 22 & 33 & 21 & 27 \\
\hline Positive Relations & 19 & 29 & 26 & 39 & 21 & 32 \\
\hline Personal Growth & 21 & 32 & 25 & 39 & 19 & 29 \\
\hline Autonomy & 19 & 29 & 29 & 44 & 17 & 27 \\
\hline Environmental Mastery & 18 & 28 & 25 & 39 & 21 & 33 \\
\hline Purpose & 20 & 30 & 17 & 27 & 28 & 43 \\
\hline Psychological Well-Being & 19 & 29 & 21 & 33 & 25 & 39 \\
\hline
\end{tabular}

Penelitian ini melibatkan 66 partisipan yang merupakan ibu rumah tangga dan berada pada tahap perkembangan dewasa awal atau 18-40 tahun. Terdapat tiga kategori data yang diperoleh, yaitu data demografi, dan psychological well-being. 
Berdasarkan tabel 1 ditemukan bahwa kebanyakan responden memiliki usia pernikahan 1-3 tahun (58\%), bekerja sebelum menikah (85\%), memiliki penghasilan keluarga sebesar 5-10 juta perbulan (36,4\%), berpendidikan S1 (65\%), tidak memiliki anak (88\%), dan memiliki peran sosial di luar rumah tangga (87\%)

Bila dilihat dari hasil uji beda menggunakan ANOVA (Tabel 2), ditemukan bahwa tidak ada perbedaan signifikan psychological well-being pada ibu rumah tangga. Perbedaan yang signifikan juga tidak ditemukan pada dimensi-dimensi psychological well-being, kecuali self-acceptance yang dibedakan berdasarkan tingkat pendidikan.

Dari tabel 3, dapat dilihat bahwa kebanyakan responden memiliki psychological well-being yang tinggi (39\%), acceptance yang rendah (35\%), positive relations yang sedang (39\%), personal growth yang sedang (39\%), autonomy yang sedang (44\%), environmental mastery yang sedang (39\%), dan purpose yang tinggi (43\%).

\section{DISKUSI}

Hasil penelitian menunjukkan bahwa mayoritas responden memiliki psychological well being yang tinggi, ini berarti responden mampu menerima dirinya, memiliki hubungan yang baik, bertumbuh, otonom, menguasai lingkungannya dan memiliki tujuan yang jelas dalam hidup.

Acceptance yang rendah ini berarti responden merasa kurang puas terhadap dirinya, dan berharap untuk menjadi orang yang berbeda dari dirinya sendiri (Ryff \& Singer, 2013). Informan 6 berkata:

"Saya sudah menerima semua ini, jadi tak ada masalah buat saya." (Informan 6, 2020)

Positive relations yang sedang berarti responden mampu mampu membina hubungan yang hangat dan penuh kepercayaan dengan orang lain. Selain itu, individu tersebut memiliki kepedulian terhadap kesejahteraan orang lain, dapat menunjukkan empati, afeksi, dan intimitas, serta memahami prinsip memberi dan menerima dalam hubungan antar pribadi. Namun, masih ada ketertutupan, ketidakpedulian, isolasi dan frustrasi serta sesekali muncul keinginan untuk menghentikan hubungan dengan orang lain (Ryff \& Singer, 2013). 
Dari hasil wawancara, ditemukan jawaban yang bervariasi. Pada informan 3 yang memiliki psychological well-being yang rendah. Ditemukan masalah dalam membangun hubungan yang positif.

"Saya korban perceraian, ayah saya selingkuh menceraikan ibu saya secara sepihak. Ayah saya tidak mau membiayai saya. Setelah berkeluarga masing-masing ibu dan ayah saya hanya fokus pada keluarga barunya dan saya diabaikan dianggap anak orang lain/dianak tirikan oleh ortu sendiri. Lalu saya juga korban KDRT suami saya." (Informan 3, 2020)

Personal growth yang sedang berarti para responden merasa adanya perasaan mengenai pertumbuhan yang berkesinambungan dalam dirinya, memandang diri sendiri sebagai individu yang selalu tumbuh dan berkembang, terbuka terhadap pengalamanpengalaman baru, memiliki kemampuan dalam menyadari potensi diri yang dimiliki, dapat merasakan peningkatan yang terjadi pada diri dan tingkah lakunya setiap waktu, serta dapat berubah menjadi pribadi yang lebih efektif dan memiliki pengetahuan yang bertambah. Akan tetapi, para responden kadang merasa dirinya mengalami stagnasi, tidak melihat peningkatan dan pengembangan diri, merasa bosan dan kehilangan minat terhadap kehidupannya, serta merasa tidak mampu dalam mengembangkan sikap dan tingkah laku yang lebih baik (Ryff \& Singer, 2013). Sebagai contoh, informan 5 berkata:

"Saya merasa masih dapat melakukan pencapaian dan mencapai target saya dalam hidup hingga saat ini."(Informan 5, 2020)

Autonomy yang sedang berarti responden dapat menentukan segala sesuatu seorang diri (self-determining) dan mandiri. Ia mampu untuk mengambil keputusan tanpa tekanan dan campur tangan orang lain. Selain itu, orang tersebut memiliki ketahanan dalam menghadapi tekanan sosial dapat mengatur tingkah laku dari dalam diri, serta dapat mengevaluasi diri dengan standar personal. Namun, terkadang responden mereasa kurang memiliki otonomi akan sangat memperhatikan dan mempertimbangkan harapan dan evaluasi dari orang lain, berpegangan pada penilaian orang lain untuk membuat keputusan penting, serta bersikap konformis terhadap tekanan sosial (Ryff \& Singer, 2013). Informan 1, yang memiliki autonomy tinggi berkata:

"Orangtua saya membuat peraturan dan norma-norma, namun juga memberikan kebebasan. Yang penting adalah saya dapat mempertanggungjawabkan kebebasan." (Informan 1, 2020) 
Environmental mastery yang sedang berarti responden memiliki keyakinan dan kompetensi dalam mengatur lingkungannya. Ia dapat mengendalikan berbagai aktivitas eksternal yang berada di lingkungannya termasuk mengatur dan mengendalikan situasi kehidupan sehari-hari, memanfaatkan kesempatan yang ada di lingkungannya, serta mampu memilih dan menciptakan lingkungan yang sesuai dengan kebutuhan dan nilainilai pribadi. Namun, sesekali ia mengalami kesulitan dalam mengatur situasi sehari-hari, merasa tidak mampu untuk mengubah atau meningkatkan kualitas lingkungan sekitarnya, kurang peka terhadap kesempatan yang ada di lingkungannya, dan kurang memiliki control terhadap lingkungannya (Ryff \& Singer, 2013). Responden 9, sempat mengalami kesulitan dalam mengendalikan lingkungan sekitar.

"Sebelum menikah, saya merasa bahwa saya adalah pribadi yg gampang beradaptasi karena saya merasa open-minded, menerima perbedaan, bisa toleransi. Namun, sepertinya kehidupan pernikahan membuat saya merasa susah beradaptasi, karena it's totally different dan tidak pernah dialami sebelumnya. Walaupun saya sudah pernah merasakan dunia kerja, sekolah, tapi awalnya menikah (pindah ke rumah suami di Serpong, agak jauh dari orang tua di Cinere), lingkungan di sana ditambah lagi mengalami infertilitas primer, membuat saya merasakan struggle untuk beradaptasi." (Informan 9, 2020)

Purpose yang tinggi berarti responden memiliki keyakinan yang memberikan tujuan hidup, serta memiliki tujuan dan target yang ingin dicapai dalam hidup (Ryff \& Singer, 2013). Informan 2 berkata:

"Tujuan hidup saya menyesuaikan diri. Sekarang saya juga punya tujuan sebagai seorang istri dan ibu yang baik." (Informan 2, 2020)

Berdasarkan hasil uji beda (Tabel 2), tidak ditemukan adanya perbedaan psychological well being yang signifikan berdasarkan usia pernikahan, status bekerja sebelum menikah, dan penghasilan per bulan mereka. Penemuan tersebut berlawanan dengan penelitian sebelumnya yang mengatakan bahwa well-being individu akan semakin menurun seiring dengan usia pernikahan. Stabilnya psychological well being tersebut bisa saja disebabkan oleh tidak adanya stres atau masalah besar dalam kehidupan rumah tangga (Kamp Dush, Taylor, \& Kroeger, 2008).

Berdasarkan ekonomi, temuan dalam penelitian ini juga berlawanan dengan temuan sebelumnya yang menyatakan semakin kaya pasangan, semakin tinggi psychological well-being mereka. Ini bisa saja disebabkan oleh tidak adanya stres 
ekonomi yang terasa pada responden dan pasangan (MacFadyen, MacFadyen, \& Prince, 1996).

Berdasarkan status pekerjaan sebelum menikah, temuan dalam penelitian ini berlawanan dengan asumsi umum yang mengatakan bahwa perempuan yang berhenti bekerja setelah menikah cenderung memiliki psychological well-being yang lebih rendah. Tidak adanya perubahan dalam well-being ini bisa saja disebabkan oleh adanya perubahan purpose dalam hidup individu. Sebagai contoh, adanya perubahan tujuan dari karier yang lancar menjadi seorang ibu rumah tangga yang baik (Kim \& McKenry, 2002).

Berdasarkan pendidikan, terdapat perbedaan signifikan pada dimensi selfacceptance. Ini senada dengan penelitian Vasile (2013) yang mengasumsikan orang dengan pendidikan lebih tinggi cenderung lebih mampu dalam mengevaluasi diri.

Berdasarkan kepemilikan anak, tidak ditemukan perbedaan psychological wellbeing yang signifikan. Menurut, Koropeckyj-Cox (2002) yang paling berpengaruh dalam psychological well-being orang dewasa bukanlah memiliki anak atau tida, tapi bagaimana gambaran kualitatif hubungan mereka sendiri.

Berdasarkan peran sosial, tidak ditemukan perbedaan psychological well-being yang signifikan. Ini berlawanan dengan temuan Brown \& Ryan (2003). Tidak ditemukannya perbedaan bisa saja disebabkan oleh adanya agensi pada Ibu Rumah tangga. Artinya, pengambilan peran sosial terjadi karena seorang perempuan memilihnya sesuai keinginan senditi tanpa paksaan.

\section{KESIMPULAN DAN SARAN}

Berdasarkan analisis hasil penelitian yang dilakukan, ditemukan bahwa ibu rumah tangga mayoritas memiliki psychological well-being sedang yang berarti para Ibu Rumah Tangga cukup mampu menerima dirinya, memiliki hubungan yang baik, bertumbuh, otonom, menguasai lingkungannya dan memiliki tujuan yang jelas dalam hidup walaupun memiliki kekurangan tertentu. Tidak ditemukan perbedaan psychological well-being yang signifikan berdasarkan faktor demografi seperti usia pernikahan, status kerja sebelum menikah, dan penghasilan.

Saran bagi peneliti selanjutnya adalah memperluas data demografi seperti jumlah anak dan menghubungkan variabel psychological well being dengan variabel lain untuk mengetahui hubungan antara mereka. Kemudian, secara metode dapat dipertimbangkan 
untuk menggunakan analisis dyadic untuk menganalisa keadaan pasangan suami istri karena dalam pernikahan, keadaan kognitif, fisik, dan psikologis pasangan saling berhubungan (Wickham \& Knee, 2012).

\section{DAFTAR PUSTAKA}

April, K. A., Dharani, B., \& Peters, K. (2012). Impact of locus of control expectancy on level of well-being. Review of European Studies. https://doi.org/10.5539/res.v4n2p124

Brown, K. W., \& Ryan, R. M. (2003). The Benefits of Being Present: Mindfulness and Its Role in Psychological Well-Being. Journal of Personality and Social Psychology. https://doi.org/10.1037/0022-3514.84.4.822

Kamp Dush, C. M., Taylor, M. G., \& Kroeger, R. A. (2008). Marital happiness and psychological well-being across the life course. Family Relations, 57(2), 211-226. https://doi.org/10.1111/j.1741-3729.2008.00495.x

Kim, H. K., \& McKenry, P. C. (2002). The relationship between marriage and psychological well-being: A longitudinal analysis. Journal of Family Issues, 23(8), 885-911. https://doi.org/10.1177/019251302237296

Koropeckyj-Cox, T. (2002). Beyond parental status: Psychological well-being in middle and old age. Journal of Marriage and Family, 64(4), 957-971. https://doi.org/10.1111/j.1741-3737.2002.00957.x

MacFadyen, A. J., MacFadyen, H. W., \& Prince, N. J. (1996). Economic stress and psychological well-being: An economic psychology framework. Journal of Economic Psychology, 17(3), 291-311. https://doi.org/10.1016/0167-4870(96)00012-8

Markus, H. R., \& Schwartz, B. (2010). Does choice mean freedom and well-being? Journal of Consumer Research. https://doi.org/10.1086/651242

Olson, D. H., Defrain, J., \& Skogrand, L. (2014). Marriages and Families Understanding Family Dynamics Models of Couples and Families Couple and Family Map. McGraw-Hill Education.

Putri, K. A. K., \& Sudhana, H. (2013). Perbedaan Tingkat Stres Pada Ibu Rumah Tangga yang Menggunakan dan Tidak Menggunakan Pembantu Rumah Tangga. Jurnal Psikologi Udayana. https://doi.org/10.24843/jpu.2013.v01.i01.p10

Rogers, C. R. (2009). Becoming a Person. In Healing: Human and divine: Man's search for health and wholeness through science, faith, and prayer. https://doi.org/10.1037/10811-003

Rotter, J. B. (1972). Applications of a social learning theory of personality. Applications of a Social Learning Theory of Personality. 
Ryff, C. D. (2013). Psychological well-being revisited: Advances in the science and practice of eudaimonia. Psychotherapy and Psychosomatics. https://doi.org/10.1159/000353263

Ryff, C. D., \& Keyes, C. L. M. (1995). The Structure of Psychological Well-Being Revisited. Journal of Personality and Social Psychology. https://doi.org/10.1037/00223514.69.4.719

Ryff, C. D., \& Singer, B. (1998). The Contours of Positive Human Health. Psychological Inquiry. https://doi.org/10.1207/s15327965pli0901_1

Ryff, C. D., \& Singer, B. H. (2008). Know thyself and become what you are: A eudaimonic approach to psychological well-being. Journal of Happiness Studies. https://doi.org/10.1007/s10902-006-9019-0

Springer. (2013). The Strength of Self-Acceptance. The Strength of Self-Acceptance. https://doi.org/10.1007/978-1-4614-6806-6

Tengland, P.-A., \& Tengland, P.-A. (2001). Marie Jahoda's Current Concepts of Positive Mental Health. In Mental Health. https://doi.org/10.1007/978-94-017-2237-7_4

Vasile, C. (2013). An Evaluation of Self-acceptance in Adults. Procedia - Social and Behavioral Sciences, 78, 605-609. https://doi.org/10.1016/j.sbspro.2013.04.360

Wade, L., \& Sharp, G. (2013). Sociological Images. Social Science Computer Review. https://doi.org/10.1177/0894439312442356

Wickham, R. E., \& Knee, C. R. (2012). Interdependence Theory and the Actor-Partner Interdependence Model: Where Theory and Method Converge. Personality and Social Psychology Review, 16(4), 375-393. https://doi.org/10.1177/1088868312447897 